service has a major partnership project that enables a completely new way to co-operate on safety related matters national wide.

Methods Mx Safety will collect and share the information regarding safety issues and is also developing tools to promote safety. Mx Safety does involve track users to recognise risks and encourage them to make improvements towards safer training conditions.

The most visible project at the moment is basic safety sign standardisation for off road tracks.

National Rescue Service co-operation offers a great opportunity to get national wide risk management, rescue and emergency guidelines for all tracks.

Results An overview of MX Safety signs was first introduced at Motorcycle Show 2015 in Helsinki, in cooperation with the MX Safety project, the cooperative network of emergency services (Pelastuslaitosten Kumppanuusverkosto) and the Finnish Motorcycling Federation. The Finnish Motorcycling Federation (SML) motocross commission has confirmed that MX Safety signs will be introduced at all Finnish motocross tracks latest during 2016. By following common guidelines and best practices and deficiencies motorcycling clubs are able to prevent significant amount of accidents. All tracks users must commit to compliance with common rules. Signs has been translated already in English, Latvian and French languages.

Conclusions Each country is welcome to work together to promote safety.

\section{MOVIT YELLOW FLAG (AUTOMATIC TRACK SAFETY SYSTEM)}

Martijn Spliethof. General Manager Movit BV, The Netherlands

\subsection{6/injuryprev-2016-042156.216}

Background For the safety of riders at motorsport accommodations 'yellow flag marshals' are present at various locations on the track. The job of these people is to warn the riders in case of a dangerous situation. In most cases a dangerous situation means that a colleague competitor has crashed within the next section of the track. Riders must anticipate by slowing down and avoid jumping. Especially the landing area behind a jump is extremely dangerous, because a rider cannot adjust the bike's route until the moment of the landing. What's the problem? In recent years a number of serious accidents happened on various tracks. These accidents could in most cases probably have been avoided with the use of flag marshals. Organisers experience more and more difficulties finding a sufficient number of good people for this important job. At international and national races they still succeed most of the time, although it may cost a lot of effort and money. At free practices and small club events there are no people available or the price is too high for the track owner. As a result there are free practices and club events without (a sufficient number of good) flag marshals. This means a high risk for competitors. In various countries, legislation is being prepared to make flag marshals mandatory during free practices.

Methods Movit Yellow Flag is an automatic system that replaces (or is additional to) the 'yellow flag marshals' at motorsport accommodations. The system provides one or more warning light signals for the competitors at a practice or race in case of a dangerous situation on the track. This works completely automatically and without human interaction. The Movit Yellow Flag system is based upon a small sending device on each motorcycle, with sensors that detect gravity and acceleration. In case a competitor crashes one or more light signals get automatically activated, so oncoming riders know that a vehicle of their colleague competitor is on the track within the next section. Riders can anticipate by slowing down and avoid jumping. At the moment the vehicle starts moving again the light signals are switched off automatically.

Results A working demo version has been developed already in 2014-2015, the production version will be available at the start of the 2016 Motocross season.

\section{Stepping up child maltreatment prevention in the World Health Organisation European Region}

\section{TUE W 4}

\section{STEPPING UP IMPLEMENTATION OF THE EUROPEAN CHILD MALTREATEMNT PREVENTION ACTION PLAN}

Dinesh Sethi. WHO Regional Office for Europe, Copenhagen, Denmark

\subsection{6/injuryprev-2016-042156.217}

Background Child maltreatment is a common public health problem globally and in Europe. The European report on preventing child maltreatment reported a prevalence of $9.4 \%$ for child sexual abuse, 23.9\% for physical abuse, 29\% for mental abuse. Investing in Children: the European Child Maltreatment Prevention Action Plan 2015-2020 has an aspirational target to reduce child maltreatment by $20 \%$ by 2020 . The Action Plan has three objectives: 1) Strengthen health systems governance by developing intersectoral national action plans to prevent child maltreatment 2) Make the problem more visible by developing surveillance systems to measure and monitor child maltreatment 3) Reduce risks by implementing child maltreatment prevention programmes. The plan was approved by 53 Member States of the WHO European Region and requests that WHO to provide support to these countries to reduce the prevalence and consequences of child maltreatment by achieving these objectives. An assessment carried out and reported in European facts and the Global status report on violence prevention 2014 shows that much work needs to be done in order to achieve these objectives. For example whereas $78 \%$ of countries reported having a child maltreatment prevention action plan, only 60\% of countries reported that they had conducted population surveys of child maltreatment. The implementation of prevention programmes was also incomplete, with a median of $44 \%$ countries that reported implementation on a large scale. If the target is to be met, then action needs scaled up markedly.

Objectives of workshop The workshop will discuss tools that are being developed by WHO to support countries. The session will provide state of the art presentations to support countries in the areas of developing national plans, improving child maltreatment surveillance and implementing prevention programmes. These will be based on handbooks that are being developed.

Workshop description The session will comprise a series of brief lectures which will set the state of the art on how to develop national action plans, on how to improve surveillance through surveys of prevalence in school children, and on what experts say on how to implement prevention programmes. This will be followed by a facilitated discussion involving policy makers, practitioners and researchers who will share country experience. Handbooks in these 3 areas will be disseminated at this session. 